\title{
O DIREITO BRASILEIRO, A PREVENÇÃO DE PASSIVO AMBIENTAL E SEUS EFEITOS NO MERCOSUL
}

Paulo Roberto Pereira de Somzal

SUMARIO: 1. Introducăo. - 2. O Direto Ambiental Brasletro. - 3. Limitacoes ao Direito de Propredade: 3. 1. Espacos Ambientais. - 4. Licentiamento de Atividades: 4. I. Tpos de Licenca. 4.1.1. Licenca Previa - 4.1.2. Licenca de lastalacăo - (L1). 4.1.3. Licenca de Operacáo-(LO). - 5. O Mercosul es Tenas Ambientats, 5.1. A ITdrovia Paraná-Paraguai. 5.2. Proptos Hidrletricos om Ambientes Compartidos. - 5.3. As Implicaçes Ambientais do Gasoduto BolviaBrosit. - 6. Probienas Ambientais Existentes e Possibilidade de Agravacäo.: 6.1. Thaftco de

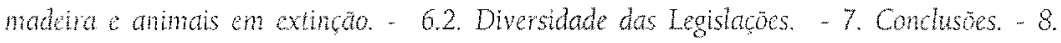
Bhliogrofia

RESUMO: Os temas ambientais cada vez mats adquirem relevo no MERCOSUL O trabalho apresenta uma análise de possfvel impactos ambientus no àmbito do MERCOSUL e mostra a preocupacáa com posshers danos ambientais que poderäo decorrer das acoes projetadas para O MERCOSUL nos próximos anos. Sugere também a unifomizaça de leis ambientas e manifesta uma preocupacáa com a necessidade da construca de um direito comunitario capaz de regular o desenvolvimento de Joma sustentavel e propiciar uma adequada tutela ao meio ambiente.

PAI AVRAS-CHAVE: Meio Ambiente, Direito Ambiental, Mercosul, Direitos Difusos, Dano Ambiental, Unidades de Conservação, Direito de Propriedade, Estudo de Impacto Ambiental, Hidrovia, Gasoduto, Florestas.

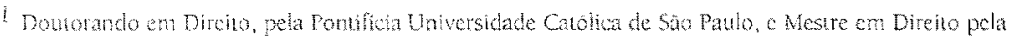
Unversidate de Londina. Prolessor de Direito Ambienta e Dieito Rocessual Civi, na Unversidade Estadual de Maringa, onde bi Reitor de 1982 a 1986.
} 


\begin{abstract}
The environmental themes are acquiring more and more importance in the MERCOSUL. The work presents an analysis of the possible environmental impacts in MERCOSUL and shows a worry with possible envirommental damage that may happen from the actions prjected for the MERCOSUL in the coming years. It also suggests an environmental law unification and shows a worry with the need of the building of a law discussed with the society and able to regulate the development in a way that will not harm the planet and give the opportunity to a adequate protection of the environment.
\end{abstract}

\title{
1. INTRODUC $\bar{A} O$
}

A partir da assinatura do Tratado de Assunção, uma intensa atividade econômica toma conta dos países que passaram a constituir o bloco de naçōes denominado MERCOSUL.

Como consequência desta intensa atividade comercial, a Argentina tomou-se o segundo parceiro internacional do Brasil, nosso fluxo de comércio com aquele representou $13,2 \%$ das exportacóes brasileiras, contra $7,3 \%$ que ocorreram no ano de 1991 , marco inicial do Mercosul, para se ter uma idéia de um comércio pouco superior a US\$ 1 bilhào em 1985. passamos para US\$ 9,6 bilhões em 19952 .

Já o intercàmbio intra-Mercosul, que não superava a 5,3 Bilhões em 1991, passou para cerca de US\$ 15 bilhões em 1995 e mais de US\$ 17 bilhöes em 19973.

\footnotetext{
2 Em a EVLUCAO DO MERCOSU. FM NOVA MOLDURA, Sebastiăo do Rego Baros, arigo publicado no Eoleim de

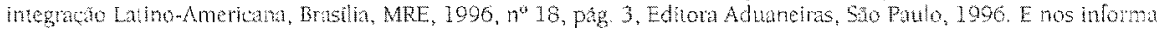
mais o Enbaxador Sebastäo do Rego Barres; Mats significativo ainda, em 1990 os três outros paises do Mercosul

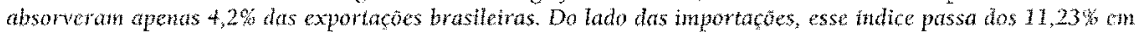
1990 para $13,95 \%$ en 1995 .. A corrente de comercio intra-Mcrcosul, en consequencia, passou de US\$3.639 milhoes em 1990 para US\$ 12.870 witheres em 1995, ou seja, am crescimento de mais de $300 \%$

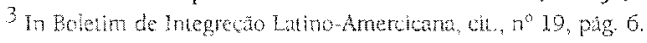


O interámbio comercial no entanto, não é o único objetivo do Tratado de Assunçąo, que prevê no seu preambulo a preservação do meio ambiente e a justica social, como parte de seus objetivos ${ }^{4}$.

A necessidade da preocupaçäo com o meio ambiente fez com que Cosse criado a Reuniăo Especializada em Meio Ambiente, que posteriomente se tomou o Sub-Grupo 6, através das decisöes tomadas em Outro Preto em 1994.

O Tratado de Assunçáo e as normas e suas nomas posteriores apresentam uma forte preocupaça com a preservaça ambiental e o desenvoivimento sustentavel.

Esta preocupacáo com o meio ambiente foi um dos pontos de destaques na Cúpula de Miami, quando os Chefes de Estado e de Governo das América, reunidos em Santa Cruz de La Siema, de 26 a 29 de novembro de 1996 realmaram o compromisso com o desenvolvimento sustentavel, ao almarem que o ser humano tem direito a uma vida saudável e produtiva, $\mathrm{em}$ hamonia com a natureza, e constitui, portanto, o centro das preocupaçós relacionadas com o desenvolvimento sustentável. É necessario que as estratégias de desenvolvimento incorporem a sustentabilidade como elemento indispensável para alcancar, de forma equilibrada, interdependente e integral, os objetivos economicos, sociais e ambientais.

Na Declaraçäo de Santa Cruz de La Sierra, destacam ainda que o desenvolvimento sustentável requer o fortalecimento e promoçáo de nossas instituições e valores democraticos, reconhecendo que a globalizaçäo, os esforços de integraçäo e a complexidade dos assuntos ambientas constituem desafios e oportunidades para os paises do Hemisfério, comprometendo-se a trabalhar em conjunto para a busca do desenvolvimento sustentável.

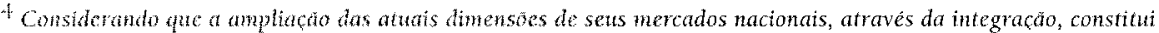
condicá fondanchital para acelerar sets processos de desenvolvimento economico com justica social. Entendendo ąte esc objeino deve ser alcançado methate o aptoveitamento mais eficaz dos recursos disponiveis,

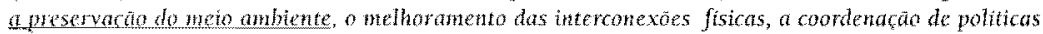
Hatneconomitas a complementatio dos diferentes setores da conomia, com base nos principios da

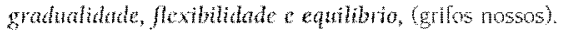


A Declaração de Santa Cruz de La Sierra, ainda evidencia a importancia de um planejamento e processo decisório onde haja compreensão e a integração de consideraçoes ambientais e de fatores sociais e economicos. Comprometem-se a avaliar o impacto ambiental das políticas, estratégias, programas e projetos a nivel nacional ou no contexto de acordos internacionais, para assegurar a identificação, prevenção, minimização ou mitigação dos impactos ambientais diversos 5 .

Consideram finalmente a importância da participaçäo pública, comprometendo-se os Presidentes e Chefes de Estado, a ampliar os espaços para a manifestaçâo das idéias $e$ o intercàmbio de informaçóes $\boldsymbol{e}$ de conhecimentos tradicionais sobre desenvolvimento sustentável entre grupos, organizações, empresas e individuos, inclusive as populaçóes indigenas, bem como para sua efetiva participação na formulação, adoção e execução das decisões que afetam suas condičoes de vida ${ }^{6}$.

Dos textos apresentados verilica-se a forte preocupação das autoridades representativas dos Estados partes do Mercosul em buscar a construção de uma sociedade sustentável.

grande desafio deste final de século consiste exatamente em buscar este equilíbrio entre um desejado desenvolvimento econômico e a preservaça da sadia qualidade de vida.

O homem chega ao linal do século contabilizando resultados altamente questionáveis. O modelo de desenvolvimento, leva todas as sociedades do planeta a uma mudança drástica das grandes referências que marcaram sua metas, pois a degradação ambiental e o quase esgotamento dos recursos naturais existe uma mudança das politicas globais e o estabelecimento de um novo paradigma tecnológico e económico.

De 1972, quando as Naçöes Unidas realizaram a Primeira Conferência Mundial sobre Meio Ambiente em Estocolmo, até 1992 o homem mudou muito sua maneira de tratar, usar e considerar os recursos naturais.

Embora todos reconheçam que o desenvolvimento e uma meta

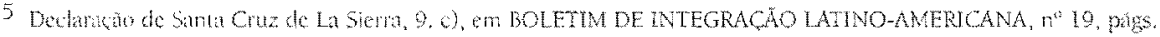
$224 \times 223$

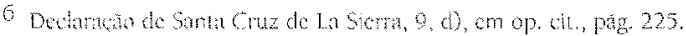


desejável, nos últimos anos cresceu a preocupação em saber se as limitações ambientais virão a restringi-lo e se o desenvolvimento causará graves danos ao meio ambiente prejudicando assim a qualidade de vida das futuras gerações.

Conseguir um desenvolvimento sustentável e equitativo continua sendo o maior desalio da raça humana.

Apesar do progresso registrado desde a última geração, mais de 1 bilhão de pessoas ainda vivem em extrema pobreza e tem acesso bastante precário aos recursos - educação, saúde, infra-estrutura, terra e crédito - de que precisam para viver uma vida melhor. A tarefa essencial do desenvolvimento é propiciar oportunidades para que essas pessoas e as centenas de milhões que se encontram em condições não muito diferentes, possam concretizar seu potencial.

O novo paradigma tecnológico e econômico vai exigir uma revisão profunda na ordem econômica e social.

A nivel cla Ciência Econômica se impõe a revisão de seus princípios básicos revendo as relações entre o homem e a natureza, integrando a introdução de valores em bens naturais até aqui não considerados cconomicamente, bem como, analisando as questões urbanas, agora com o enfoque não apenas de geração de riquezas para a satisfação das necessidades indivicluais mas a busca de um desenvolvimento sustentado. Trata-se da internalização das externalidades, onde o conceito de capital da natureza que não era considerado na formulação dos custos e das políticas empresariais, passa a ter importância decisiva na tomada de decisões por administradores públicos e privados.

O componente social do meio ambiente é de vital importância para a sobrevivência da humanidade. O sistema natural não pode mais ser estudo apenas sob a ótica das ciências naturais, pois sua preservação exige um estudo sob a ótica de ciência da natureza e ciência social.

DALIA MAIMON, nos ensina que os tomadores de decisão devem levar em conta, simultaneamente os custos sociais e ambientais; o custo no longo prazo, que escapa à caixa de ferramentas tradicionais do economista em particular da atualização de ativos ${ }^{7}$.

7 lin linsalos SORIRE ECONOMIA dO MEIO AMBIENTE, págs. 5 e 6, APED, Rio, 1992). 
O administrador público ou privado, o formulador das políticas públicas e empresariais, deve agora ter uma visäo holística do meio ambiente. JOSE A BONILLA, nos mostra que esta visão holistica se refere a um modo de compreender a realidade em função de totalidades integradas cajas propriedades năo podem ser reduzidas a unidades menores. Esta nova visão da realidade baseia-se na compreensão de que existe uma interdependência entre todos os fenômenos ou ocorrências que se relacionam com a vida humana (sejam físicos, biológicos, psicológicos, ambientais, sociais ou ainda espirituais). Devido ao reconhecimento desta ligação estrutural intima, a holistica transcende as atuais fronteiras disciplinares (e ainda conceituais) ${ }^{8}$.

Dentro dessa visão holística o ser humano passa a ser considerado como um componente do sistema total. Os humanos tem um lugar especial no sistema porque eles săo responsáveis por compreender seu papel dentro do sistema maior e de gestioná-lo para a sustentabilidade.

Esta postura contraria a visão básica da economia convencional os seres humanos, consumidores, são as figuras centrais. Seus gostos e preferências se tomam como um fato e são força dominante e determinante. A base dos recursos se toma como essencialmente inesgotavel devidos ao processo técnicos e de inflnita substituibilidade.

Para buscar a solução de uma nova ordem econômica e jurídica temos que assumir que o sistema humano é um sub-sistema dentro do sistema ecologico maior. As primeiras pergunta a fazer sobre um sub-sistema são:

- que tamanho tem com respeito ao sistema maior;

- a que tamanho pode chegar e que tamanho deveria ter?

Fstas questões de escala só muito recentemente começaram a ser consideradas. A partir da busca de respostas a tais questoes chegamos ao conceito de desenvolvimento sustentado.

O desenvolvimento sustentado é a meta macro da Economia e do Direito Ambiental, ou seja, a sustentabilidade do sistema econômico, jurídico e biológico em combinação.

8 EM ENSAOS SOBRE ECONOMIA DO MEIO AMBIENTE, págs. 5 e 6 , APED, Rio, 1992). 
A noção de sustentabilidade, significa a busca de um modelo jurídico e econômico, que satisfaça as necessidades do presente sem comprometer a capacidade das futuras geraçoes de satisfazer as suas.

Os velhos padröes de crescimento devem mudar - e rapidamente - se quisermos manter por longo tempo a integridade dos sistemas ecologicos que sustentam a vida da Terra.

Desenvolvimento sustentado é empregado com o significado de melhorar a qualidade de vida humana dentro dos limites da capacidade de suporte dos ecossistemas.

É dificil chegar a uma definiçäo exata, porém, sem dưvida, há limites na capacidade de suporte dos ecossistemas do nosso Planeta, nos impactos que os mesmos e a biosfera como um todo podem tolerar sem causar uma deterioraçăo arriscada. Os limites variam de região para região e os impactos dependem do número de pessoas presente em cada regiāo e da quantidade de alimento, agua, energia e materias-primas que cada uma dessas pessoas utiliza ou desperdica.

É impossivel a obtenção da sustentabilidade se o homen não chegar ao equilibrio entre o nivel de exploração dos recursos e a capacidade de suporte da Terra.

Para viabilizar o crescimento sustentado, de acordo com as exigências da natureza é necessário garantir um vínculo entre as políticas ambiental e econômica em todos os niveis de governo em todos os setores da economia. A harmonizaçăo da expansão coma proteção ambiental exige o reconhecimento de que há benelicios ambientais para o crescimento quando há benefícios econômicos fluindo de sistemas ecológicos saudáveis.

\section{O DIREITO AMBIENTAL BRASILEIRO}

A atividade econômica vai exigir do homem o estabelecimento de politicas harmonizadas com a variável ambiental e a garantia do cumprimento de tais políticas vamos encontrá-la a nivel do Direito Ambiental, que surge como um conjunto de princípios, instrumentos, normas e regras que buscam assegurar ao homem um meio ambiente ecologicamente equilibrado, considerado como bem de uso comum do povo e essencial à sadia qualidade de vida. 
No contexto da busca de uma sociedade equilibrada e da construção de uma conomia sustentave], o direito brasileiro integra-se a preocupaçăo que toma conta da maioria dos paises do mundo e busca integrar-se à economia e outras ciências sociais, viabilizando por meio de suas normas a efetividade do meio ambiente. Através do Direito podemos obter a consagraça das recomendaçoes dos técnicos das ciencias naturais, na viabilizaça de um meio ambiente equilibrado e sadio.

A conscientizaça ambiental exige uma nova postura do jurista, que no scu campo específico, se alia ao cientista, na elaboração agora não apenas de uma sociedade justa, - missão principal para ele até aqui - mas de um planeta habiável.

Uma nova postuma é solicitada e é iniciada uma revisão da ciência jurílica para a tutela dos chamados direitos difusos e coletivos.

Podemos dizer que estamos tratando de um super direito, elevado a nivel de Direito Constitucional9, onde a tutela näo é mais apenas do interesse individual, ferido ou ameaçado, mas de um direito que interessa a um número expressivo de timlares.

Na verdade o bem juridico tutelado é o direito à vida, assegurando-se a proleçio constitucional diante da importancia do tema para o futuro da humanidade.

A dognática juridica oferece instrumentos avançados, como a legitimação processual concedida ao Ministério Público, a organizaçoes não govemamentais que tenham entre seus objetivos a preservação do meio ambiente, consagra a responsabilidade objetiva, além de uma série de providencias processuais como concessoes liminares, etc.

O Código do Consumidor conceitua interesses ou direitos difusos, como os transindividuais, de natureza indivisivel, de que sejam titulares pessoas indeterminadas e ligadas por circunstâncias de fato e interesses ou direilos coletivos, como os transidividuais de natureza indivisivel de que scja titular grupo, categoria ou classe de pessoas ligadas entre si ou com a parte contrária por uma relaçäo jurídica base ${ }^{10}$.

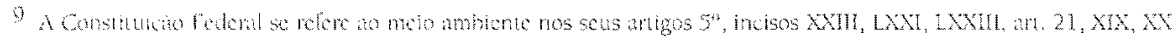

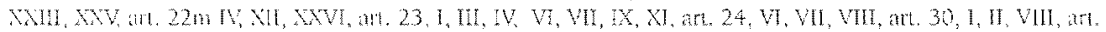

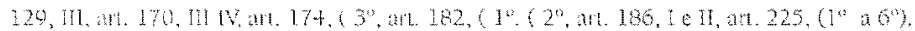

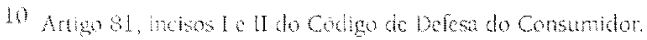


A busca do equilibrio entre o desenvolvimento econômico e o meio ambiente, passa necessariamente por uma séria ação preventiva do Direito. Destaca-se no Direito Ambiental o principio da prevençäo, que busca evitar o dano ou o perigo ao meio ambiente, uma vez que, em muitos casos os acidences ecológicos terão consequências irreparáveis.

A propósito PAULO AFONSO LEME MACHADO, lembra que o posicionamento preventivo tem por fundamento a responsabilidade no causar perigo ao meio ambiente. É um aspecto da responsabilidade negligenciado por aqueles que se acostumaram a somente visualizar a responsabilidade pelos danos causados. Da responsabilidade juridica de prevenir decorrem obrigaçōes de fazer e näo fazer ${ }^{11}$.

O principio no 17 da histórica Declaração de Estocolmo, evidencia a importäncia da prevençäo do dano ambiental, ao estabelecer que: Deve ser confiada às instituiçóes nacionais competentes, a tarefa de planificar, administrar e controlar a utilização dos recursos ambientais dos Estado, com ofim de melhorar a qualidade do meio ambiente ${ }^{12}$.

O princípio da prevenção deve ser visto como um quadro orientador de qualquer política modema do ambiente. Significa que deve ser dada prioridades a medidas que evitem o nascimento de atentados ao meio ambiente.

A Lei N. 6.938, de 31.10.81, que dispöe sobre a Política Nacional do Meio Ambiente, através de seu artigo $2^{\circ}$, dispõe que a Política Nacionąl do Meio Ambiente tem por objetivos a preservaçăo, melhoria e recuperaçäo da qualiclade ambiental, atendidos, entre outros principios os seguintes:

I - aça symemamental na manutença do equilbrio ecologico, considerando o meio ambiente como um patrimonio público a ser necessariamente assegurado e proterido, tendo em vista o uso coletivo; It - Racionalizaça do uso do solo, do subsolo, da agua e do ar; III - Planejamento e fiscalizaça do uso dos recursos

11 Em ESTUDOS DE DIREITO AMBIENAL, pigs. 30-37. Maheiros Edhorcs, 2994, Sño Paulo.

12 Path Alonso, tumben ressalia que o Forum de Siena sobre Direito Intemacional e Mero Ambiente, vedizado en 1900, desha em seu pono n, 4 a prevencho. In DANO AMBIENTAL FREVENCAO, RERARACAO E REPRESSAO,

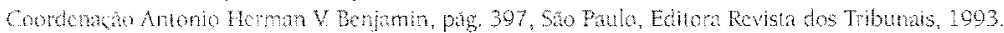


ambientais; IV - proteça dos ecossistemas, com a preservaçăo de areas representativas; $V$ - Controle $e$ zoneamento das atividades potencial oit efetivamente poluidoras; VI - Incentivos ao estudo e a pesquisa de tecnologias onientadas para o uso racionat; VII - Acompanhamento do estado da qualdade ambiental; VIII - Recuperação de áreas degradadas; LX - proteção de areas ameaçadas de degradaçâ. $X$ - Educação ambiental em todos os niveis do ensino, inclusive a educação da comunidade, objetivando capacitá-la para participação ativa na defesa do meio ambiente.

A efetividade do principio da prevençăo passa pela necessidade de se desenvolver, promover e implementar uma ética para viver de forma sustentavel.

Tal intenção é revelada no artigo $4^{\circ}$ da Lei $6.938 / 81$, que determina uma compatibilização do desenvolvimento economico-social com a preservaç̃o da qualidade do meio ambiente e do equilíbrio ecológicol3. Igualmente traz a determinação do estabelecimento de critérios e padrões da qualidade ambiental e de nomas relativas ao uso e manejo dos recursos ambientais ${ }^{14}$.

Estas regras da lei brasileira impóe um desenvolvimento harmônico e a integracão de politicas a nível macro, objetivado um desenvolvimento compativel com a preservaçāo ambiental.

A mesma Lei $N^{\circ} 6.938 / 81$, consagra o princípio do poluidor-pagador, em seu artigo $4^{\circ}$, inciso VIl, que determina a imposiçăo ao poluidor $e$ ao predador, da obrigação de recuperar elou indenizar os danos causados e, ao usuário, da contribuição pela utilização dos recursos ambientais com fins econômicos. Além disto, consagra a responsabilidade objetiva em matéria de responsabilidade civil por danos causados ao meio ambiente, determinado que sem obstar a aplicação das penalidades previstas neste artigo, é o poluidor obrigado, independentemente de existência de culpa, a indenizar ou reparar os danos causados ao meio ambiente $e$ a terceiros, afetados por sua atividade ${ }^{15}$.

Outro ponto que merece destaque é a avaliaçăo dos impactos ambientais, que se procede através do estudo prévio de impacto ambiental e relatório de impacto ao meio ambiente-EIA-RIMA. 
Estudo Prévio de Impacto Ambiental estabelecido no Brasil pelo artigo 225, \& 1\%, inciso VI da Constituição, é também instrumento da Política Nacional do Meio Ambiente ${ }^{16}$, que estabelecem a determinação ao Poder Público no sentido de exigi-lo previamente à instalação de obra ou de atividade potencialmente causadora de significativa degradaçăo do meio ambiente.

O Decreto $\mathrm{N}^{\circ} 99.274$, de 06.6.90, em seu artigo 17 prevê a exigència do EIA-RIMA, ao estabelecer que: A construção, instalação, ampliação $e$ funcionamento de estabelecimento de atividades utilizadoras de recursos ambientais, consideradas efetiva ou potencialmente poluidoras, bem assim os empreendimentos capazes, sob qualquer forma, de causar degradação ambiental, dependerão de prévio licenciamento do órgão estadual competente do sisnama, sem prejuizo de outras licenças cabiveis.

O mesmo artigo além de estabelecer a competência do CONAMA para estabelecer critérios básicos, estabelece que o estudo de impacto ambiental deverá conter, entre outros, os seguintes itens:

a - diagnóstico ambiental da área; b - descrição da ação proposta e suas alternativas $e, ; c$ - identificaçăo, análise e previsão dos impactos significativos, positivos e negativos.

Os artigos $5^{\circ}$ e $6^{\circ}$ da Resolução 001/86, do CONAMA, por sua vez obedecerá as seguintes diretrizes gerais:

I - contemplar todas as alternativas tecnológicas e de localização de projeto, confrontando-as com a hipótese de não execuça do projeto; II - identificar e avaliar sistematicamente os impactos ambientais gerados nas fases de implantaça coperação da atividade; III - definir os limites da area geografica a ser direta ou indiretamente afetada pelos impactos, denominada área de influência do projeto, considerando, em todos os casos, a bacia hidrográfica na qual se localiza; IV considerar os planos e programas governamentais, propostos e em implantação na area de influencia do projeto, e sua compatibilidade. Parăgrafo Único - diretrizes adicionais serão fixadas pelo órgào competente, quando julgar necessáno, pelas peculiaridades do projeto e caracteristicas ambientais da area, estabelecendo, inclusive os prazos para conclusäo e analise dos estudos.

16 Artigo g", inciso dII, dialci 6.93881 
O nivel de rigor do estudo prévio de impacto ambiental representou um avanço significativo do direito ambiental brasileiro, tendo sido possivel por meio de tal instrumento impedir ou mitigar danos ao meio ambiente.

Destacamos também o zoneamento ambiental, estabelecido entre nós pelo artigo $9^{\circ}$, inciso II, da Lei $6.938 / 8$ ]. Por meio de tal instrumento é possivel a limitação de atividades em áreas determinadas pelo poder público, como saturadas ou em via de serem comprometidas em termos de poluição e qualidade de vida.

O zoneamento ambiental, permite aos governos limitar o uso das propriedades, assim como disciplinar a atividade economica mantendo o equilibrio ambiental.

\section{LIMITACÕES AO DIREITO DE PROPRIEDADE}

$O$ direito de propriedade sofre limitaçoes decorrentes da lei, dos princípios gerais do direito e da própria vontade do proprietário.

As limitaços legais ao direito de propriedade decorrem da predominancia do interesse público.

O Estado, considerando-se órgão do interesse público, adota medidas restritivas ao direito de propriedade que diminuem sensivelmente o âmbito de suas virtualidades clássicas.

As limitações não representam novidade, sempre existiram, sendo que até mesmo os Código que definiam a propriedade como um direito absoluto, no se espueceram de ressalvar que o poder de dispor das coisas devia sujeitar-se às restriçoes legais.

As restriçes tem fundamento no interesse publico, social ou coletivo, e poderiam dizer respeito

ao meio ambiente, a saúde pública, a propriedade pública, a economia popular, a ordem econômica, a cultura, a higiene, ao funcionamento dos serviços públicos, ao urbanismo, a segurança pública, a defesa nacional.

As limitações mais típicas são as que atingem o exercício do direito, ou instituem deveres para o proprietátio. 
Aquele clireito subjetivo absoluto, ilimitado, intangivel cria hoje obrigaçöes para seu titular.

A propriedade deixa de ser egoísta, humaniza-se ao se relativizar, ganha conteúdo social que năo possuía, embora se conserve como direito básico de organização econômica.

\subsection{Espaços Ambientais}

A Constituição impöe ao Poder Público o dever de definir, em todas as unidades da Federação espaços territoriais e seus componentes a serem especialmente protegidos, sendo a alteração e a supressão permitidas somente através de lei, vedada qualquer utilização que comprometa a integriclade dos atributos que justifiquem sua proteção (art. $225, \S 1^{\circ}$, III).

Espaços territotiais e seus componentes, em sentido ecológico, referem-se na verdade a ecossistemas. Sua definição como tal pelo Poder Público, the conferem um regime jurídico especial, quanto à modificabilidade e quanto à fruição, natureza essa que decorre do preceito constitucional, quando diz que não podem ser alterados nem suprimidos, senão através de lei e nem ser utilizados de modo a comprometer os atributos que justifiquem sua proteção.

Quer constituam bens de domínio público ou propriedade privada, ficam eles sujeitos a um regime jurídico de interesse público pela relevância dos atributos naturais de que se revestem, postulando proteçăo especial.

A Lei 6.938/81, no inciso VI, do art. $9^{\circ}$, inclui os espaços temitoriais especialmente protegidos pelo Poder público Federal, Estadual e Municipal como instrumentos da Política Nacional do Meio Ambiente, exemplificando, como tais, com as áreas de proteção ambiental, as áreas de relevante interesse ecológico e as reservas extrativistas.

Espaços territoriais especialmente protegidos são áreas geográficas públicas ou privadas dotadas de atributos ambientais que requeiram sua sujeição, pela lei, a um regime jurídico de interesse público que implique sua 
relativa imodificabilidade e sua utilização sustentada, tendo em vista a preservação e proteção da integridade de amostras de toda a diversidade de ecossistemas, a proteção ao processo evolutivo das espécies, a preservação e proteção dos recursos naturais.

A Constituição Federal, em seu artigo 225, § $4^{\circ}$, elenca vários espaços territoriais aos quais especialmente protege, como a Floresta Amazônica, a Mata Atlântica, o Pantanal Mato-Grossense e a Zona Costeira.

\section{LICENCIAMENTO DAS ATIVIDADES}

A Política Nacional do Meio Ambiente, apresenta como um de seus instrumentos o ZONEAMENTO AMBIENTAL, o LICENCIAMENTO E A REVISÃO DAS ATIVIDADES POTENCIALMENTE POLUIDORAS. É a regra contida nos incisos II e III, do artigo $9^{\circ}$, da Lei $N^{\circ} 6.938 / 81$.

A permanente possibilidade de revisão da autorização e licença de funcionamento indica que a autorização não é por prazo indeterminado, Iniciadas as atividades de implantação e operação, antes da expedição das respectivas licenças, os dirigentes dos órgãos seccionais e da sema deverão, sob pena de responsabilidade funcional, comunicar o fato às entidades financiadoras dessas atividades, sem prejuizo da imposição de penalidades, medidas administrativas de interdição, judiciais de embargo e outras providências cautelares.

A empresa interessada não poderá iniciar suas atividades antes de obtida a necessária licença.

O Decreto 88.351/83, estabelece em seu artigo $20 \& 3^{\circ}$, que:

Expressamente alguns Estados previram em suas legislações a obrigação de ser considerado, pelos órgaõs financiadores oficiais - o cumprimento das diretrizes legais de prevenção da poluição, notadamente a observância do prévio licenciamento. Mato Grosso (art. 15, par. único, da Lei 4.894, de 25.9.85, ou Minas Gerais (art. 13 da Lei 7.772, de 8.9.80), Pernambuco (Decreto 7.269, de 5.6.81), São Paulo (art. 16 da Lei 997, de 31.5.76), Paraná, decisão do colegiado do Banco do Estado do Paraná S.A. 
As normas e criterios gerais para o licenciamento de atividades efetiva ou potencialmente poluidoras são estabelecidas pelo CONAMA, (art. $8^{\circ}$, da Lei $6.803 / 81$ ).

\subsection{Tipos de Licença}

\subsubsection{Licença Previa - (LP)}

Concedida na fase preliminar do planejamento da atividade, contendo requisitos básicos a serem atendidos nas fases de localização, instalação e operaçăo, observados os planos municipais, estaduais estaduais ou federais de uso do solo;

\subsubsection{Licença de Instalação - (LI)}

Autoriza o inicio da implantação, de acordo com as especificações constantes do Projeto do Executivo aprovado; e

\subsubsection{Licença de Operação - (LO)}

Autoriza, após as verificações necessárias ou início da atividade licenciada e funcionamento de seus equipamentos de controle de controle de poluição, de acordo com o previsto nas Licenças Prévia e de Instalação.

Dessa forma constatamos que a exigencias da legislação brasileira faz com que nossas empresas tenham que subordinar-se a uma série de exigências e custos ambientais que são internalizados no processo produtivo.

Com o advento do Mercosul, constatamos a inexistência de legislação semelhante a nivel dos Países subscritores do Tratado de Assunção, o que está gerando uma situação de desproporcionalidade de vantagens comparativas, na medida em que as empresas dos demais paises em inúmeros produtos tem custos inferiores aos custos brasileiros, em razão da desnecessidade de cumprir exigências formulados pelos órgãos ambientais e tarmbém, pelo Código de Defesa do Consumidor.

No momento em que transfere o custo ambiental para a sociedade o empreendimento econômico se viabiliza, uma vez que diminui seus custos e acaba criando uma vantagem comparativa no mercado.

Em contrapartida a empresa localizada em países onde as exigências ambientais são rigorosas, ao incorporarem tais custos em seus precos, acabam perdendo a competitividade, uma vez que o custo ambiental vai se 
refletir diretamente no preco final do produto.

Por outro lado, em países onde tais regras não säo efetivas, a sociedade acaba por ter que absorver o custo ambiental, assumindo o tratamento dos efluentes, recuperando o meio ambiente degradado. Um exemplo concreto é encontrado no Estado do Paraná que investiu mais de US\$ 150 milhöes na recuperaçăo de solos, dentro do Programa Paranaense de Recuperação e Conservação de Solos - PARANÁ - RURAL, Os agricultores que imprimiram um tratamento agressivo na mecanização do solo, destruiram as matas ciliares, resultando em erosão, assoreamento e contaminação de rios, acabaram por provocar um custo enorme por parte do Governo do Estado, na recuperação e conservação de solos.

O mesmo se pode dizer do Rio Tietê, em São Paulo, que se transformou em verdadeira bacia de drenagem de dejetos industriais, cujo custo de recuperaça devera ultrapassar meio milhão de dólares, tudo suportado pelo cidadão de São Paulo.

O custo ambiental ao invés de ser suportado pelo empreendedor estará sendo suportado pelo cidadäo, não sendo incorporado a produto, mas sim sendo pago pelos contribuintes.

\section{O MERCOSUL E OS TEMAS AMBIENTAIS}

Oterntonio do Mercosul abrange $56 \%$ do espaço ambiental da America do Sul. Num corte longitudinal, estende-se desde as espetes patagônicas, do sul da Argentina até a Floresta Amazônica ao norte do Brasil. Este espaço é rico em biodiversidade, fontes energeticas e recursos minerais; abrange importantes bacias hidrográficas, llorestas, zonas costeiras, cerrados, - pampa, o chaco, o pantanal, regioes semi-desérticas e montanhas andinas.

Estes são, simultaneamente, patrimônio ambiental e base material para o desenvolvimento.

Diante da quase inexistência de legislação ambientaî nos demais países do Mercosul, vislumbra-se a grande possibilidade de conflitos e da geração de um passivo ambiental para empresas e governos.

Podemos considerar como um passivo ambiental, um conjunto de inlraçõese de agressoes ao meio ambiente, cuja degradação itâ exigir grandes 
investimentos futuros para a sua recuperação ou restauração. Os recursos ambientais, especialmente energia e matérias-primas, bem como, os problemas resultantes da poluição industrial não tem sido considerado como custos capazes de impactar o resultado final de um produto. $O$ conceito de capital da natureza, é distinto daquele fabricado pelo homem, e tem que ser considerado como bem de uso comum de todos, com um valor económico signilicativo e que tem que ser considerado como de responsabilidade de seus usuários o pagamento pela utilização dos mesmos.

o primeiro conflito hoje existente em termos de passivo ambiental do Mercosul, decorre da falta de harmonização das leis ambientais.

Não há também uma política ambiental do Mercosul que resulte em uma aça preventiva e repressiva dos governos por danos causados ao meio ambiente.

É necessário buscar imediatamente uma internalização do custo ambiental na produça, uma vez que diante da inexistencia de legislaçăo a variavel ambiental não é considerada na formulação dos custos, bem como na formulação do conceito de eficiência econômica.

O conceito de eficiência económica deve ser revisado e ampliado, levando-se em conta não apenas os critérios de preço e qualidade do produto linal, mas fixando o conceito de acordo com os princípios do desenvolvimento sustentado.

É urgente o estabelecimento de padrões de qualidade ambiental minimos a nivel dos quatro países.

Os padröes adotados devem unifonmizar exigencias e procedimentos, de maneira a assegurar niveis iguais de competitividade, eliminando diferenças de custos de produtos e de vantagens que algumas empresas, em alguns paises encontram na falta de harmonização das leis ambientais.

A lixação dos padrões ambientais também evitará que empresas transhram investimentos de um pais para outro, em busca de vantagens competitivas representadas pela ausencia de legislação ambiental rígida. Essas empresas conhecidas como free riders em geral são empresas de poluiçăo intensa, que buscam se aproveitar dos benefícios economicos e, especialmente, das vantagens concedidas pela pobreza. Com efeito a lalta de emprego, a recessão em alguns paises do terceiro mundo fazem com que 
governantes ofereçam seus paises a tais empresas, surgindo o conhecido conflito entre a preservaçào ambiental e a superaçāo da pobreza. E é exatamente o problema da baixa renda per capita dessas populaçóes que fazem com que o consumidor não leve em conta a qualidade do produto ou mesmo se o mesmo, na sua elaboração, levou em conta ou não a preservação ambiental. Simplesmente procurará adquirir o produto mais barato.

Quem năo se lembra da música tocada no Brasil durante a Copa do Mundo de 1970 - 90 milhốes em açäo.... Éramos 90 milhöes, cm menos de trinta anos, quase dobramos a população que terá efetivamente dobrado em 2.010 .

Un conceituado instituto de pesquisa norte-americano - Population Reference Bureau Prb -, em pesquisa recentemente realizada nos mostra que na virado do século seremos 6,1 bilhöes de pessoas no mundo. $O$ mundo tem hoje 5,8 bilhões de habitantes, dos quais 4,7 bilhöes vivendo em paises em desenvolvimento, que respondem por $98 \%$ do número global de pessoas. O crescimento maior ocorrerá nos países pobres, pois os países desenvolvidos deverão permanecer com o seu tamanho de hoje: 1,2 bilhão. ${ }^{17}$ )

Em países do primeiro mundo o meio ambiente tem representado uma preocupação crescente das populaçoes, que tem levado em conta o modo de produção dos produtos, especialmente no que se refere à sua qualidacle, aos danos que o mesmo pode provocar à saúde e ao meio ambiente. $O$ selo verde tem sido um importante instrumento utilizado nos Estados Unidos, para forcar as empresas a cuidarem melhor do meio ambiente. A certificação ambiental também gerou a 1550 14000, importante certificação de qualidade, que considera entre outros itens o respeito ao meio ambiente $e$ os cuidados tomados pelas empresas para considerá-las ambientalmente corretas. Diante da ausência de leis de proteção ao consumidor na maioria dos países do Mercosul, não podemos contar muito com a pressão dos consumidores como instrumentos para compelir empresas a respeitar o meio ambiente, em açöes como boicote de compras, denuncias pela imprensa dentre outros.

17 Gazeta Mercantil, Ano LXX, ñ 21.099, 9.6.97, pàgs A-1 e A-10. 
Merece destaque ainda como ponto de possível passivo ambiental a Rodovia de Integração Sul-americana.

Importante estudo fó realizado por ocasião da Conferência sobre o Mercosul, Meio Ambiente e Aspectos Transfronteiriços - ECOSUL 96, registrando tal publicação as seguintes conclusões: 18

A empresa Louis Berger International, sediada em Washington, USA, a pedido do Banco Mundial, procedeu a um estudo preliminar de viabilidade de um projeto que se propöe a enlaçar São Paulo a Buenos Aires, através de uma auto-pista de alta velocidade, reduzindo o tempo de viagem. Foram identificados 14 traçados incluindo a ponte entre Buenos Aires e Colônia, que diminuirá a distância entre Buenos Aires e Montevidéu. A ponte teria 45 a 55 quilómetros de extensão e portanto, está destinada a converter-se numa das obras mais importantes do gênero.

Os custos do projeto da rodovia da integração apresentados pela empresa norte-americana são elevados chegando a US\$1.120,94 bilhöes, mas será de concessão privada, cujos investimentos em melhorias e custos de operação seriam recupetados por meio de pedágio e outras rendas. A execução do sistema levaria um mínimo de 10 anos.

Além dessa rodovia, há um outro projeto que objetiva a ligação do oceano Atlântico ao Pacífico, vinculado à adesão do Chile ao Mercosul, permitindo o acesso ferroviário ao Porto de Antofagasta para atender aos mercados do Oriente. Outro traçado pensado é a inter-conexão rodoviária Brasil-Perú, nos termos do Tratado de Amizade e Cooperação firmado entre os dois paises em 1981.

O passivo ambiental resultante das alteraçōes no sistema rodoviário e de transportes do Mercosul, resultariam em :

A - Na fase de construção produz-se mudanças na topografia, escoamentos, criacaco de areas de congestionamentos de tráfego e assentamentos geográficos de grande proporçoes. No caso da ponte Colonia-Buenos Aires, por exemplo, estimase que cerca de 3.000 homens estarào envolvidos na sua construçäo, contribuindo para um assentamento humano temporário, mas com impactos sócio-econômicos

18 Contome NO CICLO DA COSUY $n$ MERCOSUL M METO AMUIENTE: OPORTUNDADES E DESAFIOS PARA A GESTÃO AMBUENAL, pugs. 45 A 50, CnRiba, GTZ, 1996. 
e ambientais notonios a cidade de Colonia, que possivelmente se tornara o canteiro de obras do emprendimento.

Uma vez comstruida, a ponte permitira a comunicaçá física permanente de suas realidades sucio-economicas muto diferentes: de um lado a Regiäo Metropolitana de Buenos Aives, com 12 milhöes de habitantes contra 300.000 uruguatos do outro lado, qui habitam os Departamentos de Colonia do Sacramento, Soriano e San Jose. A agressividade comercial e financeira do mercado argentino, a desigualdade do parque motriz, a diferenca do poder aquisitivo entre um lado e outro do Rio da Prata, poderäo causar feitos econômicos, sociais, culturais e ambientais inteversueis a cidade de Colonia e a toda a costa oriental do Uruguai. O alto custo das terras nas zonas restenciais da grande Bueno Aires fara con que, em poucos anos, aneas valiosas de Colonia e seus arredores e a costa oriental do Ro da prata sejam vendidas a uma dientela de argentinos interessados em viver no Uruguai ${ }^{2}$ a trabahar (didramente em Buenos Aires) explorar os recursos naturais daquela regiăo. Cabe mencionar gue anda näo foi feito um Plano de Ordenamento Temitorial para as regioes costeiras do Uruguai.

O desuvolvintento rapido e intensivo da zona costeira que se estendera desde a cidade de Colonia ale Rocha, ambas no Urugua, em decorrência da construçăo da ponte, resulata numa pressato muto grande sobre os recursos naturas naquela regiato.

Em adicao preve-se o aumento da poluicáo do Rio da Prata naquele trecho, diminuindo o contesido de oxigento necessario à vida no rio.

$B$ - na Jase de operação, novas estradas de acesso serõo exigidas, aumentando os impaclos negativos acima mencionados. A liberalizaca dos servicos de transporte, o barateamento dos pregos dos camos, a remocão de barreiras que afetam as rodovias da industria do frete, somado as mudanças que poderio ocorrer com as atvidades economicas, iräo contribuir para un crescimento acelerado deste setor Por outro lado, nato ha uma polttica ambiental no setor de transportes do Mercosul, que deve ter uma abordagem global, devendo agir diretamente na diminuica da poluça operacional, no abrandamento da procura dispensavel de transporte, na

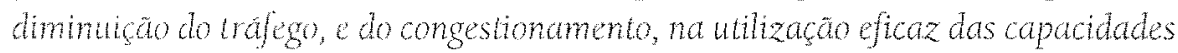
de transporte e das infra-estruturas existentes.

Dessa loma, verifica-se que são grandes os impactos decorrentes da nova estuutura rodoviária do Mercosul, impondo-se uma ampla discussão e 
Conscientizaçào da sociedade civil, quanto à alternativa a ser adotada.

Em qualquer caso a Rodovia deverá passar por um rigoroso estudo prévio de impacto ambiental. Todavia se não existir uma conscientização da populaça, especialmente dos segmentos da sociedade civil organizada, as decisoes serio tomadas nos gabinetes dos dirigentes dos países integrantes do Mercosul e dos bancos linanciadores em Washington.

\subsection{A Hidrovia Paraná-Paraguai}

O ja citado documento básico da ECOSUL 96, também nos dá uma idéa dos impactos ambientais da Hidrovia Paraná-Paraguail9.

A denominada Hidrovia Paraguai-Paraná, também denominada de Hidrovia Platense, possui $3.303 \mathrm{~km}$ de extensão, e vai de Porto Cáceres (BR) a Nucva Palmira (UR), constitui um segmento importante do sistema lluvial da Bacia do Prata e vem sendo utilizada, há muitas décadas, para atender a uma zona produtoma importante.

Atualmente, a Hidrovia Paraguai-Paraná é a principal via para o abastecimento do Paraguai e para o transporte da produça mineira de Urucum e El Mutúm, às margens do Rio.

As obras de engenharia fluvial, por sua extensão e profundidade, podera causar impactos diretos aos ecossistemas e a todo o sistema hidrologgico da Bacia do Prata, caso não seja considerada a variável ambiental. Preocupam, principalmente, as consequencias diretas que poderão causar numa das áreas úmidas maiores e mais importantes do planeta, a clo pantanal.

O clocumento citado conclui que:

O pantanal e um ecossistema com uma biodiversidade riquíssima e ainda pouco esiudada, compatithado entre Brasil, Paraguai e Bolivia. Desempenha um papel cologico inportante no controle de inundaçoes, porque constitui-se numa espécie de plantic de drenagem, que regula as enchentes do Rio Paraguai. Funciona como

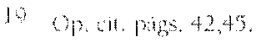


um eficiente filtro biológico que garante a qualidade de água deste importante rio. A dragagem e drenagem de $672 \mathrm{~km}$ do Rio Paraguai, nas proximidades de Corumba, no Mato Grosso, contempladas no Projeto da Hidrovia, podem alterar esse processo provocando dois tipos e efeitos:

- inundaçoses em toda a Bacia Platina pela alteração do controle hidrico natural. A retificaça dos rios navegáveis aumentaria a velocidade das aguas e, consequentemente, provocaria disturbios no regime hidrico, com a incidencia das enchentes dos rios Paraná e Paraguat. Com o aumento da correnteza, podem se reduzir em ate dois meses os periodos de cheia no Pantanal, afetando todos os paises da Bacia Platina com prejuizos que vão desde a destruição de ecossistema, até o simples desaparecimento de atividades economicas como a pecuária pantancira; - a possivel desertificaçäo do pantanal, já que o Rio Paraguai seria alterado para um maior declive e assim, passaria a exercer funçäo de dreno na região, que acabaria com muitos alagados e lagoas; - perda de enorme riqueza genética de fauna e flora, e consequências desastrosas para os povos que dela compartitham, incluindo comunidades de pescadores e populaçóes indigenas; efeitos adversos ao ambiente seriam sentidos, posteriormente, pelo incremento do trafego da Hidrovia com as obras de expansäo portuaria, o aumento da contaminacão por cargas e descargas, pelo ingresso de frotas pesqueiras e frigorificas maiores em rios, cuja legislação de proteção à pesca (epocas de reprodução) ao meio ambiente, são frágeis e com fiscalizaçăo pouco eficiente.; impactos ambientais adicionais certamente iriam ocorrer, com a expansäo da ârea produtiva ao longo da hidrovia. Considerados como impactos indiretos, mas nem por isso menos nocivos, a Hidrovia Paraná-Paraguai irá estimular a expansăo da fronteira agricola nas margens dos tres rios, pela rentabilidade do transporte. Esta expansão da agricultura poderá estimular desmatamentos e o uso de terras sem vocaça para essa atividade, principalmente a cultura da soja.

Entre os estudiosos argentinos também é grande a preocupação. Professor Raul Walter Hoschewer20, da Universidade Nacional del Litoral, nos mostra que a obra da hidrovia exigira 32 diques em diferentes afluentes dos rios que serão utilizados, a retificação de seus cursos, $e$ a dragagem de mais de oitenta e seis bilhóes de metros cubicos de barro. Como consequência imediata se

20 IMPACTO DE LA PROBIEMTICA AMBIENTAL EN EL DERECHO, Santa Fe, Agentina, Facuidade de Ciências Jumcices e Socinis da Unversidade Nacional do litom, 1977, pag. 59. 
acena com a perda de aguas, de animais e plantas silvestres assim como, mudanças climáticas.

Outro importante alerta é feito pelo Chefe de Proteção Ambiental e Educaçāo Conservacionista do Museo Argentino de Clencias Naturais de Buenos Aires, RICARDO BARBETTI21, quando mostra que a obra exigiria um bilhão e trezentos milhões de dólares para a construção e mais três bilhöes de dólares com gatos de manutenção e operação, além de:

1.) Descordem movimento das aguas, com cheias e baixas dos rios, com sequelas nas condiçóes climáticas, afetando a Formosa, Corrientes, Santa. Fé. Entre Rios e Buenos Aires.

$\left.2^{2}\right)$ Constituíça de uma via de entrada para intrusos exploradores, assim como de plantas e animais nâo originários da regiāo, muitos dos quais podem trazer doenças e pragas, transtornando de forma incontrolavel a fauna, flora e solo.

30) Seca e erosajo pelo aceleramento na velocidade das aguas, contribuindo para a extincão de plantas e animais;

40) Possivel comprometimento, em poucos anos, da represa de Yaceretá, em razão de assoreamento pelo solo a ela carreado.

5) Exploraçáo não discricionária como consequencia da necessidade de recuperar os quatro bithöes e trezentos mithöes de dotares que demandara a obra, com afetação das espécies vegetais e animais autóctonas.

Em que pese a variável económica, onde teremos uma grande queda no custo do transporte e a integração econômica total do Mercosul, a hidrovia produzirá impactos tão significativos no meio ambiente, que em uma análise de custo-benefício, ambiental e social, pode se antever o quanto a humanidade perderá com a destruição de um seus mais significativos ecossistemas.

Se näo houver uma ação dura, séria e efetiva da sociedade civil organizada poderemos em pouco tempo estarmos chorando a perda do pantanal com hoje choramos a perda dos saltos de sete quedas sepultados pelo Lago de Itaipu.

Lamentaveimente sabemos que neste tipo de decisăo näo se leva em

21 "Apud", Räil Whlter Holshewer, op e loc di. 
conta outro critério que năo o politico, o financeiro e o técnico. Tais projetos em que pese a manilestação contráia de signilicativos segmentos da sociedade, a nivel nacional e internacional, não consideram com a extensâo e profundidades exigidas a variavel ambiental, gerando impactos ambientais significativos.

\subsection{Projetos Hidrelétricos em Ambientes Compartidos}

Os principais rios de limites internacionais, são o Rio Paraná, entre Brasil e Paraguai, Rio Iguacu, entre Brasil e Argentina, Rio Uruguai, entre Brasil e Argentina e entre Urugaal e Argentina; Rio Paraguai, entre Brasil e Paraguai e o Rio da Prata, entre o Brasil, Argentina, Paraguai Unuguai e ainda a Bolívia, representando um dos maiores ecossistemas compartidos intemacionalmente.

Diante da impotancia energética da extensa bacia hidrografica compartida pelos paises do Mercosul, inicia-se um grande interesse de todos os paises integrantes do bloco.

O cocumento base da ECOSUL 96, também procede a uma análise dos projetos hidrelétricos e seus impactos no âmbito do MERCOSUL.

A construça das Usinas Hidrelétricas de Corpus e Yaceretá, no trecho do Paraguai e Argentina, uma visão da importancia da sua dimensão ambiental, quando passamos a analisar a Bacia da Prata, dentro de um macroecossistema, e que face a sua importância macroecológica deveria ser discutido o periodo do uso sustentavel e comparativo de suas águas.

No mecho superior do Rio Parana já foram construidos a UHE ILHA SOLTERIA, NO Estado de Sá Paulo, a UEH-JUPI, na divisa dos Estados de São Paulo e Mato Grosso do Sul e em fase de construção, a UEH-PORTO PRTMAVERA, tambem na divisa entre São Paulo e Mato Grosso do Sul e em Tase de constmucão, a UEH-PORTO PRIMAVERA, também na divisa entre Săo Paulo e Mato Grosso do Sul. No trecho mais inferior, a maior hidrelétrica projetada e construida, a UHE-ITAIPU, com $12.600 \mathrm{MW}$. 
Relata mais o documento da ECOSUIL 96:22

O plano energético - Brasil 2010, elaborado pela ELETROBRAS, prevé a construção de cerca de 210 usinas na região brasileira da Bacia do prata, sendo très projetos localizados no Rio Uruguai, a serem executados em consorcio internacional, quais sejam: UHE-RONCADOR, com 3.000 MW, entre o Brasil e Argentina, UHE-Guarabi, com $2.196 \mathrm{MW}$, entre o Brasil e Argentina e a UHE-São Pedro, com 731 MW ENTRE O Brasil e a Argentina.

Prevê-se ainda a construça da UHE-CHAPEDON, também no Rio Unuguai, entre o Brasil e A Argentina.

Todos esses aproveitamentos projetados para o Rio Paraná, acrescidos daqueles outros previstos, ou em operaça nos outros rios internacionais elou domésticos, obrigam que devam ser considerados seus efeitos danosos sobre regiäo do Prata, ja que a complexidade do funcionamento de equitibrio dos ecossistemas da macrorregião não obedecem aos limites polticos-administrativos estabelecidos.

Até recentemente, as questöes de impactos ambientais relacionadas à construçäo de Usina Hidreletricas tiveram uma prioridade relativamente baixa dentro do planejamento do setor elétrico.

Como se sabe, os impactos que a construça de hidrelétricas causam sobre o ambiente säo um dos mais profundos, implicando a inundaçăo de extensas áreas de terras, alterando os ambientes através da formação de extensas lages artificiais e transformando sistemas ecológicos complexos estruturados, além, é claro, da perda de patrimônio genético representado pela inundaçăo de florestas.

Grandes extensoes de terras férteis para a produção de alimentos e jazidas minerais sao suprimidas pela formação dos reservatórios da hidrelétricas, mas é em relaça a dimensão social dos impactos que mais se exterioriza a insatisfacao contra a construção das barragens, normalmente associada a compulsórias relocacoes e reassentamentos da populaçoes atingidas.

O Direito Ambiental tem tido um papel fundamental na diminuição dos impactos ambientais na construção de usinas hidrelétricas.

O conjunto de exigências para a obtenção da licença de construção e de operaça de uma barragem tem obrigado o setor elétrico a repensar o seu

22 op. ang 48,50 
planejamento, agora sobre o enfoque ambiental, prevendo consequencias, mitigando efeitos, tomando medidas efetivas de preservação ambiental.

No Brasil a implantação de novas usinas hidrelétricas, deverá submeter-se a um licenciamento especial, sendo a matéria regulada pela Resoluçăo No 006/86, CONAMA, de 6.9.87, devendo ser precedida de um estudo prévio de impacto ambiental. 23

A falta de norma de Direito Ambiental, no passado, nos mostra o quanto a sociedade fó prejudicada. As grandes obras de geração de energia do Rio Paraná, năo foram precedidas de Estudo Prévio de Impacto Ambiental-EIA-RIMA.

Itaipu é o exemplo mais concreto da falta de uma política ambiental. Quando de sua construção havia várias alternativas, entre as quais a construção de várias pequenas hidrelétricas ao longo do Rio Paraná. A megalomania dos militares, que à época governavam o País, determinou a construção não apenas de numa hidrelétrica, mas da maior hidrelétrica do mundo.

O livro Conflitos Jurídicos Econômicos e Ambientais, cuja edição coordenei, juntamente com Dr. Jon Mills, da Universidade da Florida ${ }^{24}$, registra que para a implantação da hidrelétrica foi construída a barragem principal do Projeto Itaipu, em concreto, com $1.064 \mathrm{~m}$ de comprimento e altura máxima de $196 \mathrm{~m}$ a partir do ponto mais baixo da fundação. Nessa obra foram empregados 6,5 milhỏes de metros cúbicos de concreto.

Para a implantação do reservatório na margem brasileira foi desapropriada uma área de 140.000 hectares e mais 683 hectares de área

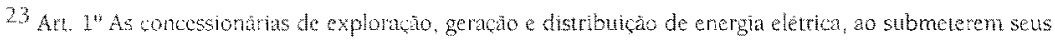

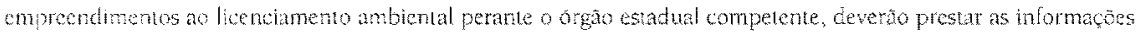

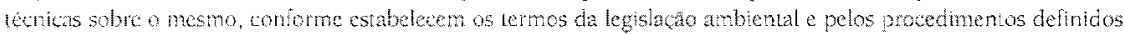
nesta besalutas

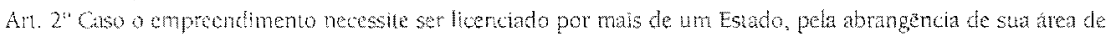

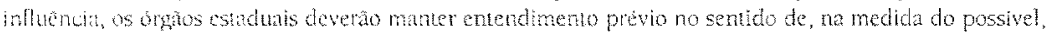
unibraizu as exignclas.

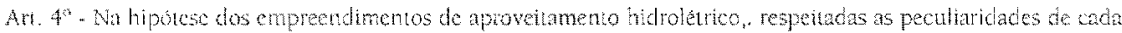

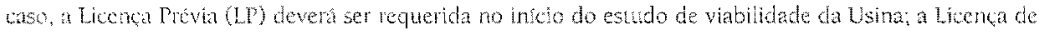

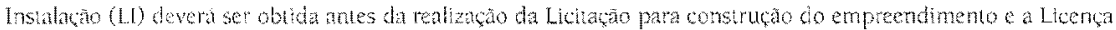
de Operate (Lo) devera ser obtida antes do fechmento da banagem.

24 CONFLTOS JURTHCOS, ECONOMLOS E AMBIENTAIS, Coordenatores Fanlo Roberto perena de Souza e Jon Mills, Marmgin, EDUTM, 1995, pig. eltat,
} 
remanescentes, compreendendo 8.500 propriedades, sendo 6.900 rurais e 1.600 urbanas.

Da area arrendada 60.000 hectares de florestas nativas e o restantes terras agricolas das mais férteis do País. Provocou-se alteração nas águas subterrâneas, na fauna e flora, no micro-clima da região e na economia regional, que perdeu um dos maiores potenciais turísticos do País.

Os impactos socioeconômicos, foram significativos, uma vez que a inundaçăo das terras causou perdas à economia regional e grande impacto social em razão da desapropriação das terras, posto que $86,1 \%$ dos imoveis expropriados eram constituidos de minifúndios.

Também o documento base da ECOSUL 96, analisando os impactos das hidrelétricas a nivel do MERCOSUL, conclui que:25

Numa analise bastante abrangente, pode-se dizer que os principais problemas de impactos sócio-ambientais apresentados por hidreletricas construidas etou em implantaçán na Bacia do Prata, podem ser:

- cilteraçóes em sitios de relevante importância para a biodiversidade, com reduçăo imediata da variedade de fauna e flora regional; - alteraçoes microclimáticas; desapropriaçoes em âreas altamente férteis e produtiva, desfavorecendo $O$ equilibrio da cconomia da natureza na relaçăo custo $X$ beneficio economico $X$ ecologico; - alteraçoes profundas na relaçoes politico-intencionais e socioeconomicas nas unidades territoriais alingidas; - desarticulação dos sistemas produtivos; - perda de parte da infra-estutura regional; - insatisfaça social e fomentaça de litigios e desagregacáo, principalmente na questão indigena; incapacidade do setor elétrico de encarar a Bacia do Rio da Prata, como um macroecossistema compartido por outros patses näo levando em conta os impactos sobre esse sistema que poderão se refletir internacionalmente, e, - ausencia de articulaça de maior envergadura, a nivel de Chanceleres dos paises envolvidos na Bacia do Prata, de maneira a discutir uma matriz energética para toda a região e a questâo do setor hidrelétrico em particular, de maneira a compatibilizar os diversos usos previstos (hidrovia, temoelétrica, gasoduto) com a conservaça desse machossistema.

25 op ait pig, 50 . 
Para prevenir os impactos ambientais capazes de gerar passivo ambiental signilicativo, urge a hamonizaça da leis ambientais dos paises membros do Mercosul, em especial no que se refere ao EIA-RIMA, integrando o debate e soluçäo da questão entre as autoridades dos diversos paises.

\subsection{As Implicaçoes Ambientais do Gasoduto Bolivia-Brasil}

A nivel de uma análise puramente econômica, à luz da economia convencional, podemos concluir positivamente em relação à construção do gasoduto Bolívia-Brasil.

Hoje o Brasil comercializa, com suas proprias reservas, pouco mais de 8 mithōes de metros cúbicos de gás natural por dia.

As reservas bolivianas são suficientes para abastecer o mercado brasileiro, inicialmente como 8 milhões de metros cúbicos de gás natural por dia, crescendo em sete anos até 16 milhôes de metros cúbicos por dia, valor que poderá se manter por 13 anos, equivalente a 100 mil barris de petróleo por dia.

O gasoduto tem impactos positivos, no que se refere à socioeconomia, como possibilidade de aquecimento da economia local, na Bolivia e no Brasil, pelo aumento dos postos de trabalho, direitos e indiretos; por uma demanda maior de bens e serviços, com o surgimento de pequenos comércios, especialmente nas cidades localizadas próximas aos canteiros de obras, ou pelo aumentos das arrecadaçoes municipais, o que permitirá novos investimencos por partes das Prefeituras locais.

En relaça ao meio fisico iniciam os impactos com a abertura de acesso, faixa de domínio, implantação de canteiros de obras e alojamentos.

O documento base da ECOSUL-96, nos mostra os principais impactos ambientais do gasoduto, quais sejam:

- alteração do cotidiano da população; - exposição da população ao risco de acidentes; - alteração do quadro demográfico; - perda de produção agrossilvopastoril; - aumento da demanda por bens e serviços; - aumento do trálego de veículos;- alteração no quadro de saúde; - pressões sobre os equipamentos de saúde; - interferência com o património arqueológico; - 
aumento da emissão de midos e poeiras; - desvios ou aceleração de processos erosivos; - instabilizaçäo de encostas; - alteraçoes no uso das terras; - carreamento de sólidos; - assoreamento da rede de drenagem; alteraçoes ou eliminação da vegetação existente; - alteração da comunidade aquática local; - aumento da caça e pesca predatória; - alteração no habitat e nos hábitos da fauna:26

Na lase de construção e montagem, a escavação da vala é uma açâo impactante para o patrimonio local. Uma outra ação também relevante é a instalacão das estaçoes de compressão e medição, especialmente para o meio lísico-biótico.

A operação do gasoduto tem como impacto negativo principal, a exposiça da populaça ao risco de acidentes, o que cria uma série de expectativas nos moradores das regioes diretamente afetadas. Tal risco exigira a adoção de medidas de segurança próprias com a implantaça de programas de comunicação social e emergenciais, que poderäo minimizar tais impactos

\section{PROBLEMAS AMBIENTAIS EXISTENTES E POSSIBILIDADES DE AGRAVAÇÃO}

\subsection{Tráfico de madeira e animais em extinção}

A exploração predatória de madeira no Brasil e nos paises do Mercosul, tcm gerado um tráfico ilegal de tais produtos que são exportados, com o uso de guias halsas, com a construção de uma verdadeira teia de corrupção, ameaçando a grande diversidade biologica da América Latina.

A biodiversidade engloba plantas, animais, microorganismos e, de maneira geral, os ecossistemas e processos ecológicos dos quais são componentes.

Até hoje năo se determinou com a extensão e a profundidade necessirias, a importância da diversidade genética das florestas tropicais

26 op. ch pros 54,58 
brasileiras. Alguns espécimes ainda se encontram em fase de mutação genética, relevando-se a importância de sua preservação.

A nivel no MERCOSUL, inúmeros problemas se apresentam, como o grande comércio de peles silvestres, sem uma legislação mais rigida capaz de coibir tal prática, que chega a superar o comércio de couros de espécies domésticas.

A expansäo da fronteira agricola notadamente no Brasil, Argentina e Paraguai, gera uma grande pressão sobre ecossistemas frágeis, com a expansăo da atividade agricola e pecuária, gerando grandes desmatamentos inclusive em áreas de solos sensiveis de vida útil curta, que acabam se transformando em desertos em curto espaço de tempo

O crescente corte ilegal de madeira praticado por empresários brasileiros, especialmente na Provincia de Missiones e no Paraguai, na região de fronteira com o Brasil, representam outro impacto significativo, resultando na destruição de espécies centenárias e raras.

O Paraguai, tem na exploraçăo de suas florestas e na caça clandestina as principais causas de destruição da sua biodiversidade. O contrabando de madeira na extensa fronteira seca do Departamento de Amambay e Mato Grosso do Sul diante da dificuldade de fiscalização e controle tem se tornado cada vez mais forte e crescente..

Este fato gerou a assinatura de um Acordo Binacional entre o Brasil e - Paraguai para o controle ilícito de comercialização de madeira.

O que realmente assusta é a ineficácia da legislação existente. Com eleito, o Paraguai editou em 1992 a Lei n 96, que regula a Vida Silvestre, a qual define em seu artigo $2^{\circ}$ que por fauna silvestre, se entenderá todos aqueles vegetais, superiores ou inferiores que, temporal ou permanentemente, têm o território nacional como área de distribuição biogeográfica. Em importante manifestação do sistema juridico daquele país, declara de interesse social e de utilidade pública a proteção, manejo e conservaçăo da vida silvestre do País, que passa a ser regulada pela referida let, assim como, sua incorporação à economia nacional. Considera que todos os habitantes tem o dever de proteger a vida silvestre do país ${ }^{27}$.

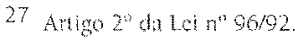


Exige uma licença e consulta da Autoridad de Aplicación ${ }^{28}$, para toda obra pública ou privada, como desmatamento, drenagem de terras úmidas, construções de barragens, que possam causar transformações no ambiente da vida silvestre nativa, hipótese em que será exigido um estudo prévio de impacto ambiental. Já o artigo 37 proíbe a exportação, importação e reexportação de todas as espécies da fauna silvestre.

Também o artigo $7^{\circ}$ da Lei 294/93, exige o estudo prévio de impacto ambiental, na exploração agrícola, pecuária, florestal e granjeira. Tal lei foi regulamentada pelo Decreto 14.281/96, que determina em seu artigo $5^{\circ}, \mathrm{n}^{\circ}$ 3 , exige o estudo de impacto ambiental nos projetos de exploração florestal que tenham lugar em terrenos com extensão superior a 50 hectares de aproveitamento.

Outro fato preocupante, é a acelerada ocupação do solo com grandes áreas desmatadas na região Ocidental do Paraguai, no Chaco, efetuadas por imigrantes brasileiros.

O Paraguai, tem na exploração de suas florestas e na caça clandestina as principais causas de destruição da sua biodiversidade.

O baixo valor da terra tem gerado um uso predatório das mesmas uma vez que seus proprietários não investem em conservação do solo, gerando grande erosão e degradação do solo.

\subsection{Diversidade das Legislações}

No caso do Paraguai novamente emerge a falta de efetividade das normas ambientais como o grande desafio dos países do MERCOSUL. Há um corpo de lei expressivo, que oferecem boas condições para a proteção ambiental, no entanto tais leis não são cumpridas. Em muitos casos foram resultados de exigências de organismos internacionais e não foram assumidas pelos formuladores e executores de políticas públicas, assim como năo são conhecidas pela maior parte da população.

28 Que é a Diretoria de Parques Nacionais e Vida Silvestre, subordinada ao Vice-Ministro de Recursos Naturais e Meio Ambiente do Ministerio de Agricultura y Ganaderia. 
Assim o contrabando de madeira e a acelerada destruição da cobertura florestal do Paraguai continua impune e crescente, exigindo uma açäo internacional e uma pressăo a nivel do Sub-grupo 6 para que busque caminhos capazes de diminuir as agressōes ambientais que ocorrem no vizinho Pais.

No Uruguai, $4 \%$ das terras situadas na fronteira com o Brasil (Departamentos de Artigas e Rivera), são de propriedade de brasileirosgaúchos, que desenvolvem a pecuária, o cultivo da soja e, principalmente, do arroz. A expansão do cultivo do arroz, tanto por brasileiros quanto por uruguaios nos últimos anos, vem ameaçando uma área conhecida como Los humedales del Este ou Banhados de Rocha, ecossistema protegido pela Convençăo de Ramsar, em funçäo das obras de irrigaça que vem sendo construidas.

No Paraguai, após a construção da Hidrelétrica de Itaipu no Rio Paraná, milhares de brasileiros migraram para o lado paraguaio (municípios de Amambay, Alto Paraná, Canindeyu e Itapua), para o cultivo de soja. Hoje, săo cerca de 350.000 brasileiros que vivem no Paraguai, e que são responsáveis por aproximadamente, $65 \%$ da soja produzida naquele País. Esta ocupaçäo estrangeira e nacional contribuiu para que $50 \%$ das norestas nativas do Paraguai lossem dizimadas nos últimos 30 anos, ou seja, cerca de 400.000 hectares de florestas.

Na Argentina o problema maior é a falta de uma lei nacional em matéria ambiental, uma vez que os estados provinciais - Estados Provinciales - têm poderes para legislar entre outras matêrias sobre meio ambiente ${ }^{29}$.

Dessa forma, como observa LEILA DEVIA ${ }^{30}$ corresponde à Nação

29 A Argentina cono Estado teve origem ass acotos que no Provincias celobram entre si para critb. Assimo antigo 104 da Consituitito da Argentina (autal 121) determina que: As Provincias conservam fodo o poder nato

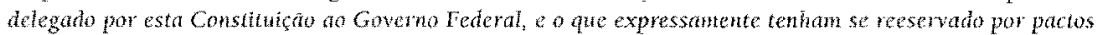
especiais at tenpo de sua incorporaçăo. Sobre matéra ambiental as Provincias nâo delegnran suas faculdades. Hoje nos temos to artigo 41, hat uma regra naconal constiluctonal determinando o direito a um ambiente sadio, equilibrado e apto para o desenvolvimento humano e para que as atividades produtivas satisfacam as necessidades presentes sem comproneter as das geraços futuras e tem o dever de preservă-lo. $O$ dano mibiental geran prioritariamente a obrigacăo de recompor o neio ambiente, segundo o estabeleca a let.

30 LEGSLACAO AMBIENTAL DA REPUBUCA ARGENTINA, M MERCOSUR Y MEDIO AMDIENTE BUENO Aires. Ediciones Cludad Argentina, 1996, pag 33. 
ditar as normas que contenham os pressupostos minimos de proteção, e às províncias, as necessárias para complementá-las, sem que aquelas alterem a jurisdiçăo local.

A nivel local a maioria das Constituições provinciais, consagraram anteriormente à Constituiçăo Nacional os direitos a um meio ambiente sadio, como aconteceu com La Rioja (art. 66), San Juan (art. 58), San Luis (art. 47), Salla (arts. 30 e 78), Santiago del Estero (arts. 30 e 58), Río Negro (arts. 84 e 85) e Cóndoba (art. 66)31.

Outro problema que dificulta uma tutela efetiva do meio ambiente na Argentina é a falta de uniformidade quanto à lei processual. Não há uma lei nacional sobre direitos dilusos, sendo que apenas algumas Provincias, como Santa Fe - Lei 10.000/87 - e, San Juan - Lei 6006 - instituiram legislação especifica para a tutela de direitos difusos. A nivel federal, on em outras provincias, apenas através da doutrina e jurisprudência

A harmonização das leis ambientais e dos meios de tutela do meio ambiente como bem jurídico de interesse comum do povo, direito de terceira geração, difuso e condição para assegurar a vida é hoje um dos grandes desalios entre outros temas candentes que ocupam as atençoes dos operadores do MERCOSUL.

\section{CONCLUSÖES}

A inexistencia de programas de conservação de solos tem gerando um enorme passivo ambiental em todos os paises do Mercosul, para se ter uma idéia só o Estado do Paraná gastou mais de US\$200 milhões em programas de conservaçăo de solos e implantação de microbacias hidrográficas, custo que, posteriormente, é suportado por todos os cidadãos.

A lalla de legislação sobre agrotóxicos na maioria dos paises do Mercosul tem resultado em graves problemas ambientais, com

31 Conl. Leila divia, op. cit, pag. 86. 
consequencias especialmente sobre o Pantanal, o Chaco paraguaio e a pampa úmida Argentina. Pesticidas proibidos em seus países de origem estão sendo comercializados em parte dos países do Mercosul por falta de uma lei ambiental adequada.

A harmonizaça de politicas ambientais e de leis ambientais é imperativo para a busca de melhoria da qualidade de vida das populações do Mercosul. Eurgente uma aça integrada dos paises membros para prevenir o enorme passivo ambiental que está sendo gerado, pela atividade econômica, em consequência ou da inexistência ou do desrespeito à lei.

É necessário o aperfeiçoamento de mecanismos de cooperação regional para uma atuação coordenada entre os paises e organismos internacionais com vistas à preservação do meio ambiente.

As populaçoes dos países membros tem que ser adequadamente informadas sobre os impactos ambientais decorrentes do passivo ambiental que está sendo gerado, bem como, de sua extensão, profundidade e consequências.

É imperativo a criação de programas de educação ambiental capazes de conscientizar a populaçäo motivando-a a ter uma participaçäo mais efetiva no debate dos temas ambientais e em pressionar govemos, governantes, formuladores e executores de politicas públicas para fazer triunfar a supremacia do interesse coletivo.

O conceito de desenvolvimento sustentável deve estar presente na formulação das politicas, economica, industrial, agricola e ambiental dos Estados partes do Tratado de Assunção.

A inexistência de um sistema judiciário do Mercosul, tem dificultado a aplicação das leis e uma ação internacional, na preservação de ecossistemas que năo podem ser tratados de acordo com divisas geográficas ou políticas, mas sim de forma integral, sob pena de comprometimento. Assim, impóe-se a criaçäo de um Tribunal supranacional com Jurisdição em todo o Mercosul, para o julgamento de causas envolvendo interesses dos paises, a nível público e privado.

A pressäo exercida sobre os países de terceiro mundo pode 
comprometer nossa qualidade de vida, pois no balanço entre a preservação ambiental e a geração de empregos, a miséria e a fome, fica extremamente difícil manter uma posição em favor do meio ambiente.

Impōe-se também a criação de um Parlamento do Mercosul, que hoje possui apenas uma Comissão Parlamentar Conjunta, sem poderes legislativos, para, a exemplo do Parlamento Europeu, poder formular um direito comunitário, que possa tutelar os direitos individuais e coletivos, públicos e privados.

A intensa atividade econômica que tomou conta dos países membros do MERCOSUL, especialmente Brasil e Argentina, nāo pode prevalecer sobre o interesse coletivo na preservação da qualidade de vida das populaçōes.

As grandes obras que estão sendo cogitadas deverão ser submetidas a um rigoroso estudo prévio de impacto ambiental o qual deve ser precedido de audiência pública internacional, para fixação de diretrizes e determinação de área de abrangência e de impactos a serem avaliados.

A globalização da economia vem exercendo grande pressão sobre empresas e países, exigindo cada vez mais controle de custos na busca permanente de competitividade dos produtos, todavia também não podemos abrir mão de conceitos duramente construídos como o de desenvolvimento sustentável, flexibilizando exigências ambientais para instalação e funcionamento de empreendimentos poluidores.

A realidade nos mostra que temos um enorme desafio pela frente. Um novo paradigma tecnológico e social exigirá de todos nós uma mudança de postura, mudando nossas atitudes assumindo uma posição pro ativa para a construção de uma sociedade mais justa e de um mundo melhor. 


\section{REFERENCIAS BIBLIOGRAFICAS}

BARROS, Sebastăo do Rego. Evolução do Mercosul em nova moldura, artigo publicado no Boletim de integracăo Latino-Americana, Brasilia, MRE, 1996, n 18, Editora Aduaneiras, Sa Paulo, 1996.

BOLETIM DE INTEGRAC̄̃O LATINO-AMERICANA, Brasilia, MRE, 1996, nº 19, Editora Aduaneiras, São Paulo, 1996

BONILLA, José A. Enfoque holistica, meio ambiente e administraçâo, trabalho apresentado na XV Reviño Anual da ANPAD, de 24 a 26.9.90, em Florianópolis, encartado nos Anais da referida Retnião, Vol. 6, pag. 95.

DEVIA, Lsila. Legislaça ambiental da República Argentina, em MERCOSUR Y MEDIO AMBIENTE, Buenos Aires, Ediciones Ciudad Argentina, 1906.

GAZETA MERCANTLL Ano LXXV, no 21.099, 9.6.97, págs, A-l e A-10.

GOVERNO DO PARANA GTZ, No ciclo da ECOSUL - MERCOSUL e meio ambiente: oportunidades e desafios para a gestăo ambiental, págs. 45 A 50, Curitiba, GTZ, 1996.

HOSCHFWER, Ratil Walter. Impacto de la problemática ambiental en el derecho, Santa Fe, Argentina, Faculdade de Ciências Juncicas e Sociais da Unversidade Nacional do Litoral, 1977. pág. 59.

LEME MACFADO Paulo Afonso. Estudos de Direito Ambiental, Malheiros Editores, 1994, Săo Paulo.

- PRINCIPOS GERAIS DE DIRETO AMBIENTAL INTERNACIONAL E A POLITICA AMBIENTAL BRASLEIRA, em Dano Ambienta Prevençăo, Reparacăo e Repressão, Coordenaça Antonio Herman V Benjamin, São Paulo, Edirona Revista dos Trbunais, 1993.

MAIMON, Dalia, Ensaios sobre economia do melo ambiente, APED, Rio, 1992.

SOUZA, Paulo Roberto Perita de, MLLS, Jon, Coordenadores Conllitos juridicos, económicos e ambientais, Maringa, EDUEM, 1995. 